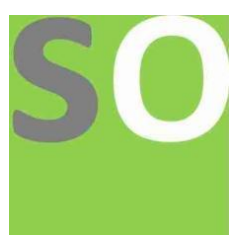

Article title: ClinicalReportsonEarlyDiagnosisofNovelCoronavirus (2019-nCoV)PneumoniainStealthlnfectedPatients Authors: Le Yang[1]

Affiliations: test[1]

Orcid ids: 0000-0002-9732-1243[1]

Contact e-mail: markleyang@qq.com

License information: This work has been published open access under Creative Commons Attribution License $\mathrm{http}: / / c r e a t i v e c o m m o n s . o r g / l i c e n s e s / b y / 4.0 /$, which permits unrestricted use, distribution, and reproduction in any medium, provided the original work is properly cited. Conditions, terms of use and publishing policy can be found at https://www.scienceopen.com/.

Preprint statement: This article is a preprint and has not been peer-reviewed, under consideration and submitted to ScienceOpen Research Preprints for open peer review.

DOI: 10.14293/S1111.000/000004.v1

Preprint first posted online: 11 February 2020 


\section{Clinical Reports on Early Diagnosis of Novel Coronavirus (2019-nCoV) Pneumonia in Stealth Infected Patients}

Zhou Yang, Yang le, Han Ming, Huang Minqiang, Sun Xuedong, Zhen Weidong,Xu Junqing, Wang JinHong *and Han Wei*

Wang JinHong address:

Department of Medical Imaging, Shanghai Mental Health Center, Shanghai Jiao Tong University School of Medicine, Shanghai, PR. China.

Office Tel: 86-21-34773624

E-mail: jinhongw2004@foxmail.com

* The authors are equally contributed

Corresponding Author: Han Wei

Emergency Department of Shenzhen University General Hospital, Shenzhen, Guangdong, China

Shenzhen medical and health services “Sanming” Project ( SZSM201911007 ) 


\begin{abstract}
An outbreak of novel coronavirus(2019-nCoV) that began in Wuhan, China, is rapidly spreading to all over China, and gradually to multiple countries. Regarding to put the epidemic prevention and spread under the control, early identification and diagnosis play a critical role. Patients with initially no or mild symptoms of Novel Coronavirus Pneumonia (2019-nCoV), namely "stealth" infection, often lack of typical clinical evidence to establish the diagnosis. Based on the clinical analysis of 4 cases in stealth infection, the results of this study highlight that early diagnosis requires a combination of epidemiological history, clinical manifestations, early chest CT examination, and 2019-nCoV RNA test (nucleic acid test), with particular emphasis on definite epidemiological history and early chest CT findings when positive nucleic acid tests lag behind.
\end{abstract}

\title{
Introduction
}

An outbreak of pneumonia caused by the Novel Coronavirus (2019-nCoV) first started in December 2019 in Wuhan, China, but cases have been identified in a growing number of other international locations (1). A cluster of cases of 2019-nCoV pneumonia were reported and associated with the Huanan Seafood Wholesale Market in Wuhan, Hubei Province $(2,3)$. Current epidemiologic data indicate that person-to-person transmissions of 2019-nCoV are spreading rapidly (4). A preliminary understanding of the disease has been acquired in the course of managing patients at medical centers. However, studies of early identification and diagnosis are needed, especially for stealth infected patients with high suspicion and lack of etiological evidence. This clinical analysis of 4 confirmed patients in common type of the 2019-nCoV pneumonia is as follows.

\section{Clinical Characteristics}

From January to February 2020, 4 confirmed patients (3 young females, 1 elderly male) with common type of 2019-nCoV pneumonia were hospitalized and treated. And 4 patients had a history of close contact with the epidemic area in Wuhan or 
confirmed patients. All 4 patients had fever $\left(\left\langle 38.5^{\circ} \mathrm{C}\right)\right.$, while fatigue, headache, cough and pharynx discomfort were found in 2cases, respectively; and sputum, muscle soreness in 1 case, respectively(Table 1). No symptoms of nasal congestion,, runny nose, vomiting, diarrhea, chest tightness, or shortness of breath were found in all 4 patients. Chest physical examination showed no positive signs, such as dry and wet rales, in both lungs. Significant reduction in peripheral blood leukocytes and lymphocytes were seen in only 1 case. Throat swab 2019-nCoV RNA tests showed initially negative in 1 case, initially positive in 2 cases, and twice negative in 1 case (Table 2). Chest X-ray examinations presented negative in 3 patients. Multiple patchy shadows, interstitial changes, ground glass shadows on CT images were observed in all 4cases, and a small amount of bilateral pleural effusion in one case (Figure 1-4).

Table 1. Clinical Manifestation

\begin{tabular}{|c|c|c|c|c|c|c|c|}
\hline & Fever & $\begin{array}{c}\text { Sore } \\
\text { Throat }\end{array}$ & $\begin{array}{c}\text { Dry } \\
\text { Cough }\end{array}$ & $\begin{array}{l}\text { Productive } \\
\text { Cough }\end{array}$ & Headache & $\begin{array}{c}\text { Muscle } \\
\text { Pain }\end{array}$ & Fatigue \\
\hline Case 1 & & & & & & & \\
\hline Case2 & & & & & & & \\
\hline Case3 & & & & & & & \\
\hline Case4 & & & & & & & \\
\hline
\end{tabular}


Table 2. Symptom, Image, and 2019-nCoV RNA Test Results

\begin{tabular}{|c|c|c|c|c|c|c|c|c|c|c|c|c|}
\hline \multicolumn{2}{|c|}{ Close contact days } & 1 & 3 & 7 & 8 & 9 & 10 & 11 & 12 & 13 & 16 & 17 \\
\hline \multirow{3}{*}{ Case1 } & Symptom & & & & $\sqrt{ }$ & $\sqrt{ }$ & $\sqrt{ }$ & $\sqrt{ }$ & & & & \\
\hline & Image & & & & & $\triangle$ & k & & & & & \\
\hline & 2019-nCoVRNA & & & & & $\square$ & & 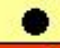 & & & & \\
\hline \multirow{3}{*}{ Case2 } & Symptom & & & $\sqrt{ }$ & 2 & $\checkmark$ & $\sqrt{ }$ & $\checkmark$ & $\sqrt{ }$ & $\sqrt{ }$ & $\sqrt{ }$ & $\checkmark$ \\
\hline & Image & & & & & & & & & & t & \\
\hline & 2019-nCoV RNA & & & & & $\square$ & $\square$ & & & & & ○ \\
\hline \multirow{3}{*}{ Case3 } & Symptom & & & & & & & $\sqrt{ }$ & $\sqrt{ }$ & $\sqrt{ }$ & & \\
\hline & Image & & & & & & & $\triangle$ & \ & & & \\
\hline & 2019-nCoVRNA & & & & & & & & & ? & & \\
\hline \multirow{3}{*}{ Case4 } & Symptom & $\sqrt{ }$ & $\sqrt{ }$ & $\sqrt{ }$ & & & & & & & & \\
\hline & Image & & $\Delta \star$ & & & & & & & & & \\
\hline & 2019-nCoVRNA & & & 口 & & & & & & & & \\
\hline \multicolumn{6}{|c|}{$\begin{array}{l}\text { Comments: } \\
\text { X-Ray: } \triangle \text { Negative; A Positive; } \\
\text { CT: \& Negative; } \text { \& Positive; } \\
\text { Oropharyngeal Swabs: } \square \text { Negative; } \\
\text { Nasopharyngeal Swabs: } \bigcirc \text { Negative; }\end{array}$} & $\lambda S 1$ & & & & & & \\
\hline
\end{tabular}

Figure 1. Case 1

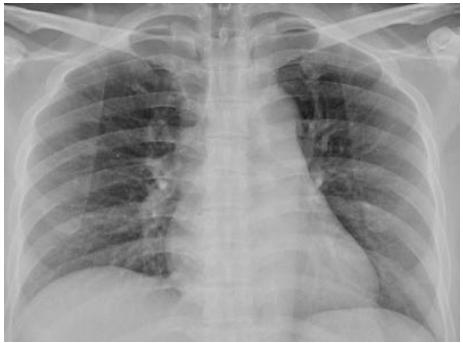

Negative Chest X-ray; lung
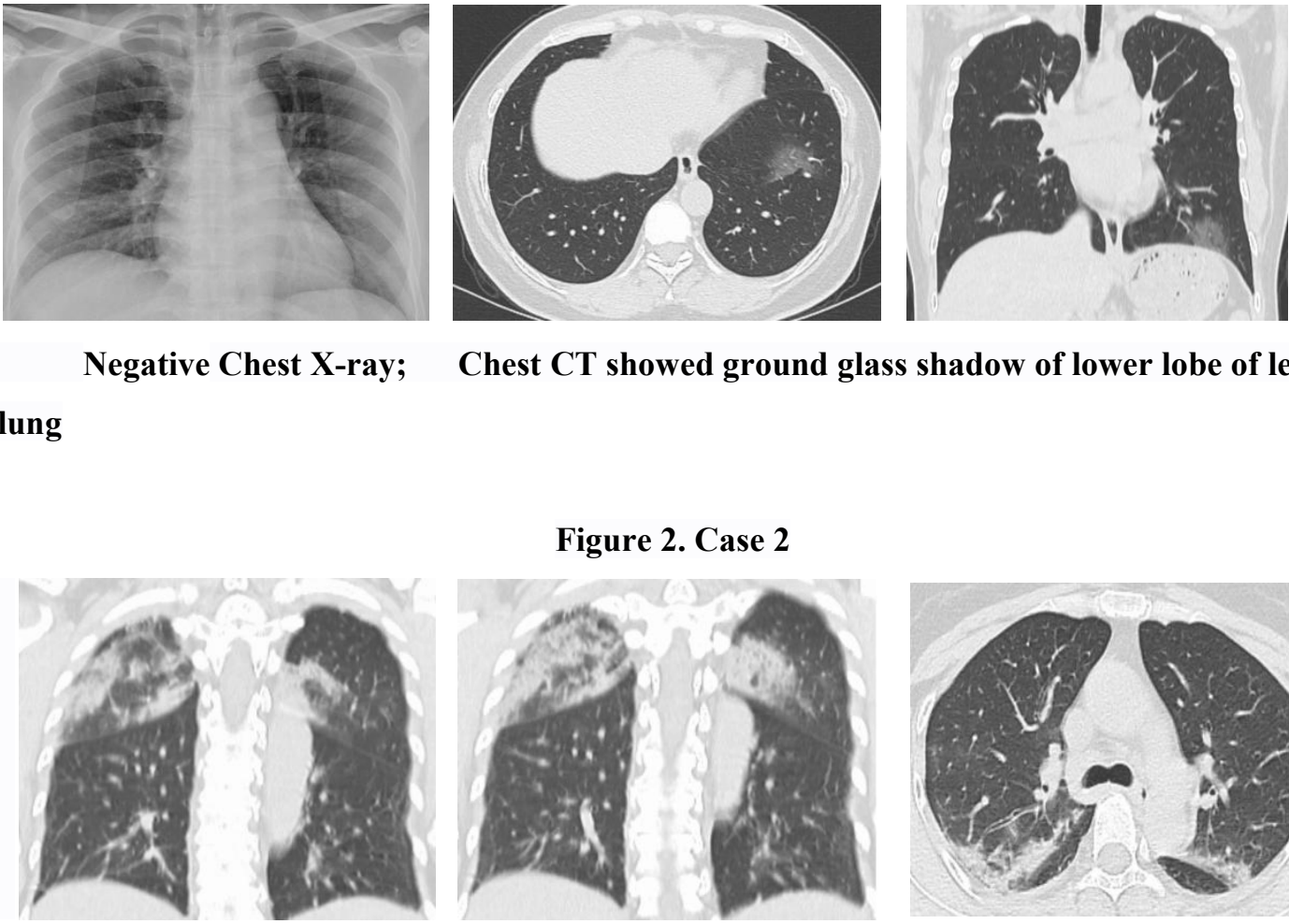

Chest CT showed ground glass shadow of lower lobe of left

Figure 2. Case 2
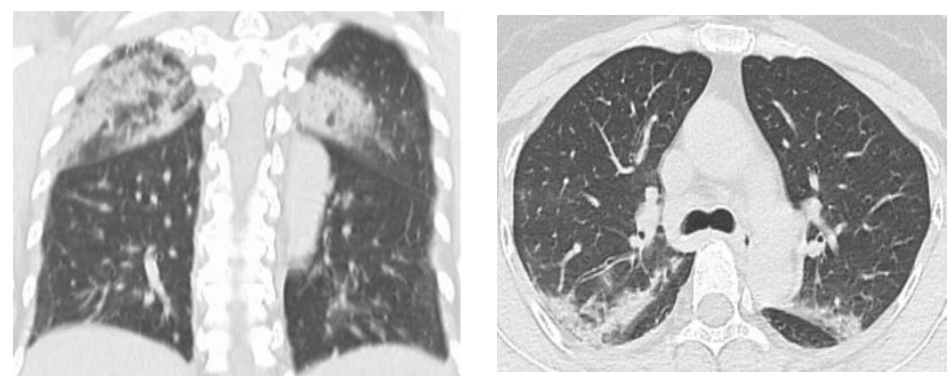

Chest CT images showed multiple patchy shadows and a few pleural effusions bilaterally

Figure 3. Case 3 

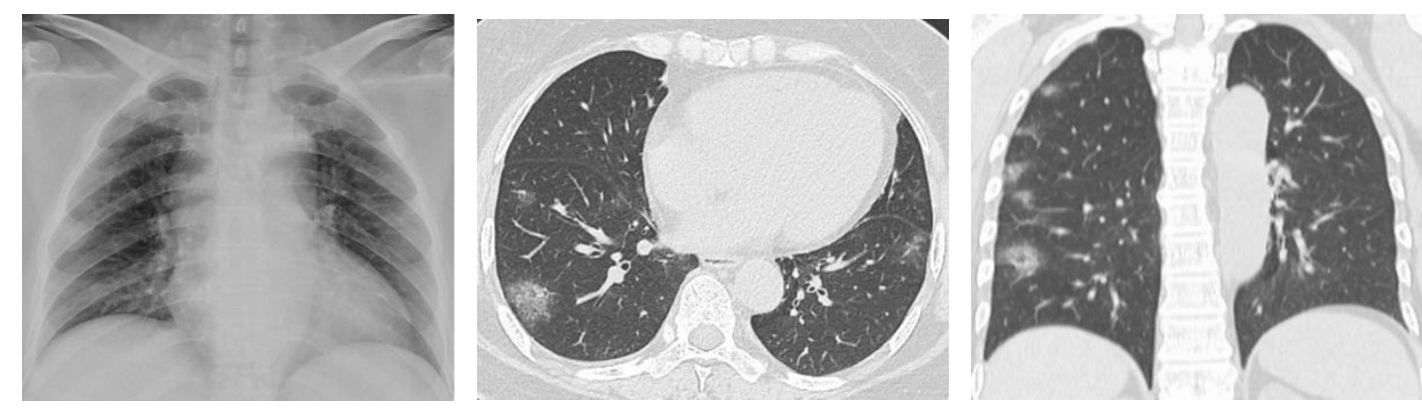

Negative Chest X-ray; Chest CT images showed multiple patchy distribution of ground glass shadows in both lungs

Figure 4. Case 4
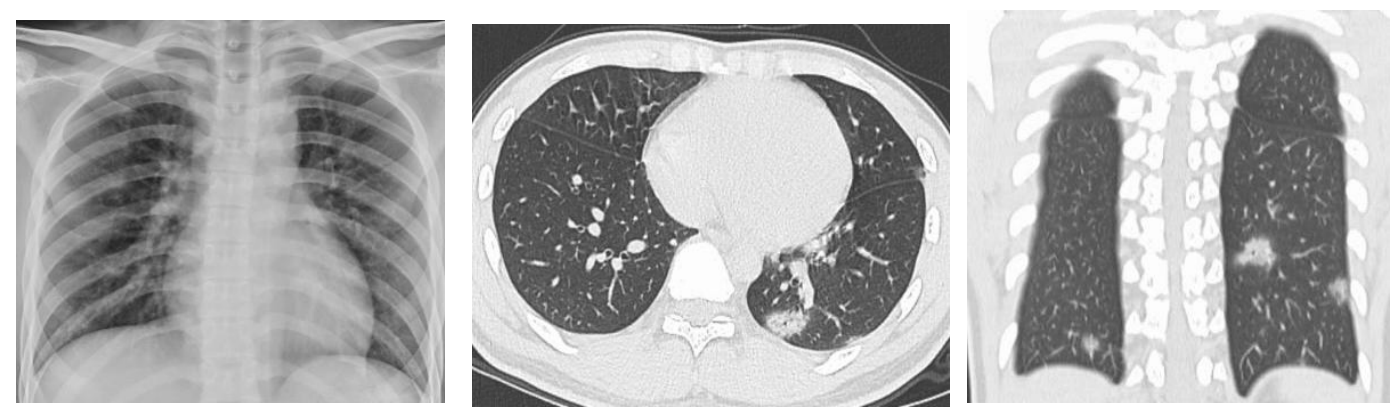

Negative Chest X-ray; Chest CT images showed multiple patchy distribution of ground glass shadows in both lungs

\section{Discussion}

In the course of disease development of the four confirmed cases, we found that: 1 . the patients all had mild clinical symptoms presenting stealth infection; 2 . Chest images showed negative X-ray findings but moderate-to- severe CT manifestations; 3. false negative and delayed positive results were found in 2019-nCoVRNA tests of respiratory tract specimens. 4 . there are still some deficiencies in the management of the outbreak of this 2019 -nCoV pneumonia.

Cases 1 and 2 were negative for the first 2019-nCoV RNA test, and one case was still negative for the second test. In the end, the two patients were tested positive for 2019-nCoV RNA on day 11 and day 17 after close contact, respectively, rather than immediately positive after the onset of symptoms. The false negative results might be considered to be related to the following factors: 1. Disease progression: the patients do not carry enough viral loads to be detected positive. 2. Sampling sites of respiratory secretions: the current sampling sites are mainly: oropharynx and nasopharynx. The two patients were sampled from oropharynx when the test results were negative, and positive from nasopharynx. It has been reported that the positive 
detection rate of 2019-nCoV RNA from oropharyngeal sampling alone is lower than that of nasopharyngeal sampling. The reason for the difference in results may be that the environment of nasopharynx and oropharynx has an impact on 2019-nCoV; the patient's tolerance resulted in the swab staying longer in the nasopharynx than in the oropharynx at the time of sampling. In addition, oropharyngeal sampling is more likely to cause droplet spray and occupational exposure. 3. The different results in detection may be related to the technical experience of the sampler, testing method, test kit, specimen preservation and transportation. To briefly sum up, the results of 2019-nCoV RNA detection from single, single site and single sample are not reliable. The results of 2019-nCoV RNA from multiple, multiple sites and multiple specimens are of great significance for the etiological diagnosis. Case 2 was tested positive for 2019-nCoV RNA on the 17th day after close contact, indicating that 14 days of isolation may not be sufficient for some cases, thus leading stealth spread of the 2019-nCoV.

According to the Tianjin Centers for Disease Control and Prevention, the 28th patient in Tianjin had negative 2019-nCoV RNA tests twice on the 6th day after the first day of fever, and fever again on the 8th day, but the test was still negative on the 9th day, eventually the 4th test on the 11th day showing positive. Case 2 in our study was similar to the above reported case from Tianjin disease control and prevention center.

In China, 2019-nCoV RNA was detected out in the feces of some confirmed patients with 2019-nCoV pneumonia, indicating that 2019-nCoV is likely to be transmitted through fecal-oral pathway. According to literature reports (5), 2019-nCoV can enter host cells through the cell receptor angiotensin converting enzyme 2 (ACE2). ACE2 is not only highly expressed in type II alveolar epithelial cells, esophageal epithelium, and stratified epithelial cells, but also in absorptive intestinal epithelial cells of the ileum and the colon. The above study, based on bioinformatics analysis of single-cell transcriptomes, suggests that the digestive tract may be a potential infection pathway for 2019-nCov. This may also be the cause of gastrointestinal symptoms in some patients with the Novel Coronavirus Pneumonia. In short conclusion, it remains to be further studied whether the early diagnosis and follow-up of 2019-nCoV infected patients require the detection of 2019-nCoV RNA in feces, urine and other body fluids. 
A few of prominent clinical characteristics of the four patients in stealth infection were that the clinical signs and symptoms were inconsistent with the image findings, presenting mild signs and symptoms but moderate-to-severe CT findings. According to the clinical manifestations, all 4 cases had mild symptoms in common type of 2019-nCoV pneumonia, but moderate-to-severe chest CT findings showing multiple patchy distributions of peripheral ground glass shadows and interstitial changes, suggesting viral pneumonia. And one case had bilateral pleural effusion. However, no positive manifestations were found on the chest X-rays before CT examinations in 3 patients. For suspected patients, especially those who have no etiological evidence, chest X-ray examination alone is often unable to comprehensively and objectively evaluate the pulmonary conditions. Therefore, the early chest CT examination is recommended to reduce the missed diagnosis. Further study regarding quantitative chest CT in large sample size, is need to evaluate the diagnostic value of $2019-\mathrm{nCoV}$ pneumonia.

At last, we strongly recommend: 1. Early diagnosis of stealth infected patients should not be limited to two negative 2019-nCoV RNA tests; 2 . Early chest CT examination, multiple samplings, multiple sample sites, combined with definite history of epidemiology, are needed to make a early diagnosis and decrease misdiagnosis and missed diagnosis of 2019-nCoV pneumonia, though stealth infected patients can present no or mild clinical manifestations and laboratory tests. In particular, attention should be paid to definite epidemiological history and chest $\mathrm{CT}$.

\section{Reference}

[1] Michelle L. Holshue, M.P.H., Chas DeBolt, M.P.H et al.First Case of 2019 Novel Coronavirus in the United States[J]. The New England Journal of Medicine, 2020.1.31. doi:10.1056/NEJMoa2001191

[2] Pneumonia diagnosis and treatment for novel coronavirus infection (5th edition), national health commission of China,2020,1,27 
[3] World Health Organization. Pneumonia of unknown cause-China.2020

(https://www.who.int/csr/don/05-january-2020-pneumonia-of-unkown-cause-china/en )

[4] Chan JF-W, Yuan S, Kok K-H, et al. A familial cluster of pneumonia associated with the 2019 novel coronavirus indicating person-to-person transmission: a study of a family cluster. Lancet 2020 January 24.

[5] Hao Zhang, Zijian Kang, Haiyi Gong, et al. The digestive system is a potential route of 2019-nCov infection: a bioinformatics analysis based on single-cell transcriptomes $[\mathrm{J}]$. bioRxiv preprint first posted online. 2020.1.31; doi: http://dx.doi.org/10.1101/2020.01.30.927806. 